\title{
Melt Conditioning Twin Roll Casting with Thermo-Mechanical Treatment of Recycled AA6111 Alloy
}

\author{
KAWTHER AL-HELAL $\left(1,{ }^{1,2}\right.$ JAYESH PATEL, ${ }^{1}$ and ZHONGYUN FAN ${ }^{1}$ \\ 1.-BCAST, Brunel University London, Uxbridge UB8 3PH, UK. 2.-e-mail: \\ kawther.al-helal2@brunel.ac.uk
}

\begin{abstract}
A high shear melt conditioning twin roll casting process with thermo-mechanical treatment was tested to increase the tolerance to high impurity levels in recycled aluminium alloy. Applying high shear melt conditioning prior to casting of recycled AA6111 alloy exhibits reduced centre-line segregation and a fine equiaxed grain structure with improved sheet quality. Homogenisation at $540^{\circ} \mathrm{C}$ for $8 \mathrm{~h}$ with annealing at $520^{\circ} \mathrm{C}$ for $10 \mathrm{~min}$ of the melt-conditioned twin roll casting strip (MC-TRC) showed a clear grain recrystallisation, which was better than the conventional twin roll casting TRC strip. The mechanical test showed a significant improvement in the hardness after applying high shear melt conditioning with thermo-mechanical treatment.
\end{abstract}

\section{INTRODUCTION}

Because of the increasing demand for weight reduction in the automobile industries, aluminium sheets have great potential to replace heavy metals. ${ }^{1}$ The heat-treatable AA6111 aluminium alloy has received significant interest from the automobile industries because it can be shaped after the heat solution treatment. ${ }^{2}$ It possesses high strength and excellent stretch-forming characteristics. Using recycled aluminium alloys or developing an economical process is the best strategy to reduce the cost of producing aluminium alloy sheets. The great challenge for the low-cost aluminium industry is the control of the inclusion content. Upon recycling, a certain amount of $\mathrm{Fe}$ contents and other inclusions will contaminate the original $\mathrm{Al}$ alloys, which are detrimental to the mechanical properties. The effect and formation of $\mathrm{Fe}$ intermetallics on the tensile properties have been widely investigated. ${ }^{3}$ The fabrication process of $6 \mathrm{xxx}$ alloy sheets consists of casting, homogenisation, rolling, annealing, ageing, forming and paint baking. ${ }^{4}$ The casting conditions, chemical composition and homogenisation process are the most effective parameters for the morphology and volume fraction of the Fe intermetallic. Homogenisation for aluminium alloys sheets is a very important process before further processing. In the as-cast microstructure of AA6111, the phase constituents are often $\mathrm{Mg}_{2} \mathrm{Si}, \mathrm{CuAl}_{2}, \quad \beta-\mathrm{Al}_{5} \mathrm{FeSi}$,
$\mathrm{AlCuMgSi}$ and $\alpha$-AlFeMnSi. ${ }^{5}$ Most of $\mathrm{CuAl}_{2}$, $\mathrm{AlCuMgSi}$ and $\mathrm{Mg}_{2} \mathrm{Si}$ will dissolve and plate-like $\beta-\mathrm{Al}_{5} \mathrm{FeSi}$ particles will transform into spherical $\alpha$ AlFeMnSi particles during the homogenisation process. ${ }^{6}$ The undissolved coarse particles of the $\mathrm{Fe}$ - or Mn-rich phases will deteriorate the thermo-mechanical performance. ${ }^{7}$ Rapid solidification is the best method for improving the mechanical properties of recycled aluminium alloy. The twin roll casting TRC process can accomplish rapid solidification and offer an economic process to produce aluminium sheets from recycled aluminium alloy. Traditionally, TRC has been limited to relatively pure aluminium alloys largely because of the tendency for more alloyed materials to stick to the caster rolls and/or develop microstructures with internal and surface defects that are unsuitable for further downstream processing. The most common casting defects in the twin roll cast sheet can be categorised into surface defects or bleeds, internal defects such as centre-line segregation and macroscopic buckling. ${ }^{9}$

Melt conditioning technology is a process for conditioning liquid metal prior to casting using a high-shear rotor-stator device at a temperature around the liquidus temperature. The melt conditioned twin roll casting (MC-TRC) process is a new technology developed by applying melt conditioning prior to the twin roll casting (TRC) process. The main advantages of melt conditioning are 
homogenisation of the chemical composition and temperature close to the solidification front, improvement of chemical reactions and an increase of the wettability of existing solid particles in the liquid metal. ${ }^{10} \mathrm{As}$ a result, grain refinement by the physical action can be achieved by using the high shear prior to twin roll casting. The fragmented and dispersed existing oxides can act as heterogeneous nucleation sites and overcome the limitations of conventional twin roll casting. ${ }^{11,12}$ Kumar et al. ${ }^{13}$ applied melt conditioning with the addition of a grain refiner in processing AA5754 scrap analogue alloys in the MC-TRC process. The results showed fine equiaxed grains distributed throughout the strip with eliminated centre-line segregation compared with the conventional TRC process with improved formability.

Nilam et al. ${ }^{14}$ demonstrated in their study that by using HSMC for the Al-3 Mg alloy, the MC-TRC strip showed $22 \%$ higher elongation with high and uniform plastic deformation compared with twin roll casting TRC.

The aim of this study was to investigate the effect of high shear melt conditioning on the microstructure of recycled AA6111 alloy and the possibility of reducing casting defects such as centre-line segregation and to increase the impurity tolerance in casting recycled aluminium alloy in twin roll casting. Experiments for conventional and melt conditioned twin roll casting were conducted by using recycled AA6111 aluminium alloy followed by thermo-mechanical treatment.

\section{EXPERIMENTAL PROCEDURES}

\section{Equipment and Materials}

A small-scale version of a horizontal twin roll caster was used in this study. The TRC machine consists of two stainless steel rolls. Each roll is $318 \mathrm{~mm}$ in diameter and $350 \mathrm{~mm}$ in width, vertically opposed to one another, and the strip exits horizontally. The rolls are internally water-cooled and each roll is driven independently by an electric motor and gearbox. The gap between the rolls is set manually, and the maximum peripheral roll speed was around $15 \mathrm{~m} / \mathrm{min}$.

Experiments were carried out using the HSMC box and tundish/tip assembly made of N17 refractory board. The HSMC device consists of a rotorstator assembly made from a special material capable of working in molten aluminium; more details about the device and assembly have been described in previous publications. ${ }^{14}$ Once the melt has been poured into the chamber, the sheared material overflows into the tundish/tip assembly and then into the roll bite. AA6111 process scrap alloy, supplied by Primetals Ltd., with the composition shown in Table I, was used in the current study. Experiments were conducted first to optimise the operating conditions such as pouring temperature, casting speed and setback for a range of roll gaps for both conventional TRC and MC-TRC. For a $2.5-\mathrm{mm}$ roll gap, the optimum operating conditions were a $35-\mathrm{mm}$ setback and a roll speed of 3.0 RPM. Trials using a simple tundish/tip arrangement found that the optimum temperature of the melt in the tip is around $660^{\circ} \mathrm{C}$ and the melt pouring temperature was $668^{\circ} \mathrm{C}$. In MC-TRC experiments, the preheated mixer was inserted at the centre of the feeding HSMC box, which was filled, with a melt at $668^{\circ} \mathrm{C}$ and shearing started prior to adding the melt for continuous operation. The shearing speed of the rotor-stator device was 3000 RPM. Strips of AA6111 alloys were successfully cast for conventional TRC and MC-TRC processes with $3.2 \mathrm{~mm}$ thickness and $110 \mathrm{~mm}$ width.

\section{Thermo-Mechanical Treatment and Mechanical Testing}

For thermo-mechanical treatment, samples from strips were taken towards the end of the as-cast strip to ensure that the process was as close to a steady state as possible within the limits of the machine. The as-cast strips were homogenised at $540^{\circ} \mathrm{C}$ for $8 \mathrm{~h}$ and then quenched in water. The thickness of homogenised strips was reduced by cold rolling to $2.0 \mathrm{~mm}$ and $1.0 \mathrm{~mm}$. Cold rolled strips were annealed at either $450^{\circ} \mathrm{C}$ for $1 \mathrm{~h}$ or $520^{\circ} \mathrm{C}$ for $10 \mathrm{~min}$ and followed by air cooling to room temperature.

\section{Characterisation}

For metallography characterisations, samples along three dimensions-parallel to the rolling direction (RD), transverse direction (TD) and normal direction ND-were mounted in Bakelite, ground and polished with $0.04 \mu \mathrm{m}$ silica in a water suspension. Anodisation of polished samples was carried out at $20 \mathrm{~V}$ for $90 \mathrm{~s}$ in Barker's reagent to reveal the grain size and morphology. A Zeiss AxioVision optical microscope was used for microstructural analysis on the transverse and longitudinal sections of the TRC and MC-TRC strips. The linear intercept method was implemented to measure the average grain size on polarised images. Samples of

Table I. As-received composition of AA6111 process scrap alloy

\begin{tabular}{llllllllll}
\hline Composition & $\frac{\mathbf{M g}}{0.95}$ & $\frac{\mathbf{M n}}{0.22}$ & $\frac{\mathbf{F e}}{0.37}$ & $\frac{\mathbf{S i}}{0.88}$ & $\frac{\mathbf{C r}}{0.01}$ & $\frac{\mathbf{Z n}}{0.02}$ & $\frac{\mathbf{T i}}{0.03}$ & $\frac{\mathbf{C u}}{0.91}$ & $\frac{\mathbf{A l}}{\text { Wt.\% }}$
\end{tabular}


different roll gaps and process conditions and along three dimensions were polished for the hardness test. The hardness test was performed using a 10kg-load Vickers hardness tester. Data were determined from the average of seven readings from each sample.

\section{RESULTS AND DISCUSSION}

\section{Microstructure and Characterisation of AA-6111 Alloy}

Long strips from the conventional TRC and MCTRC were successfully cast under optimum operating conditions for a 2.5-mm gap. Micrographs of the transverse (TD), longitudinal (RD) and normal (ND) directions from the conventional TRC and MC-TRC process are shown in Figs. 1, 2 and 3. The micrographs show large dendritic grains, abnormal grain growth, a non-homogeneous matrix structure and a continuous centre line of the conventional TRC, as shown in Figs. 1a, c, 2a, c and 3a, c, while the ascast MC-TRC micrographs show a relatively fine equiaxed grain structure and a homogeneous matrix structure with discrete centre-line channels, as shown in Figs. $1 b, d, 2 b, d$ and $3 b, d$. The average grain size of the conventional TRC and MC-TRC in the transverse section was $230 \mu \mathrm{m}$ and $130 \mu \mathrm{m}$, respectively.

The observed centre-line segregation is because segregation of solute elements exists in the melt to the centre of the strip. These elements diffuse from the solid/liquid interfaces of the growing columnar grains to the centre of the strip and the soluteenriched liquid metal may squeeze from the mushy zone at the centre to the hot region of the sump. ${ }^{15}$

There is a tendency to form centre-line segregates when casting wide freezing range alloys such as AA5754 and AA6111. The degree of centre-line segregation is a function of the shape of the liquid metal sump. The deeper the sump (V-shaped), the worse the problem is. Ideally, the flatter the sump (tending to a U shape) is, the better. In MC-TRC casting, the solidification mechanism is dominated by a heterogeneous nucleation by oxide particles. This results in an equiaxed solidification front across the transverse section and reduction of the solute segregation towards the centre. Accordingly, the sump depth will reduce and the deformation
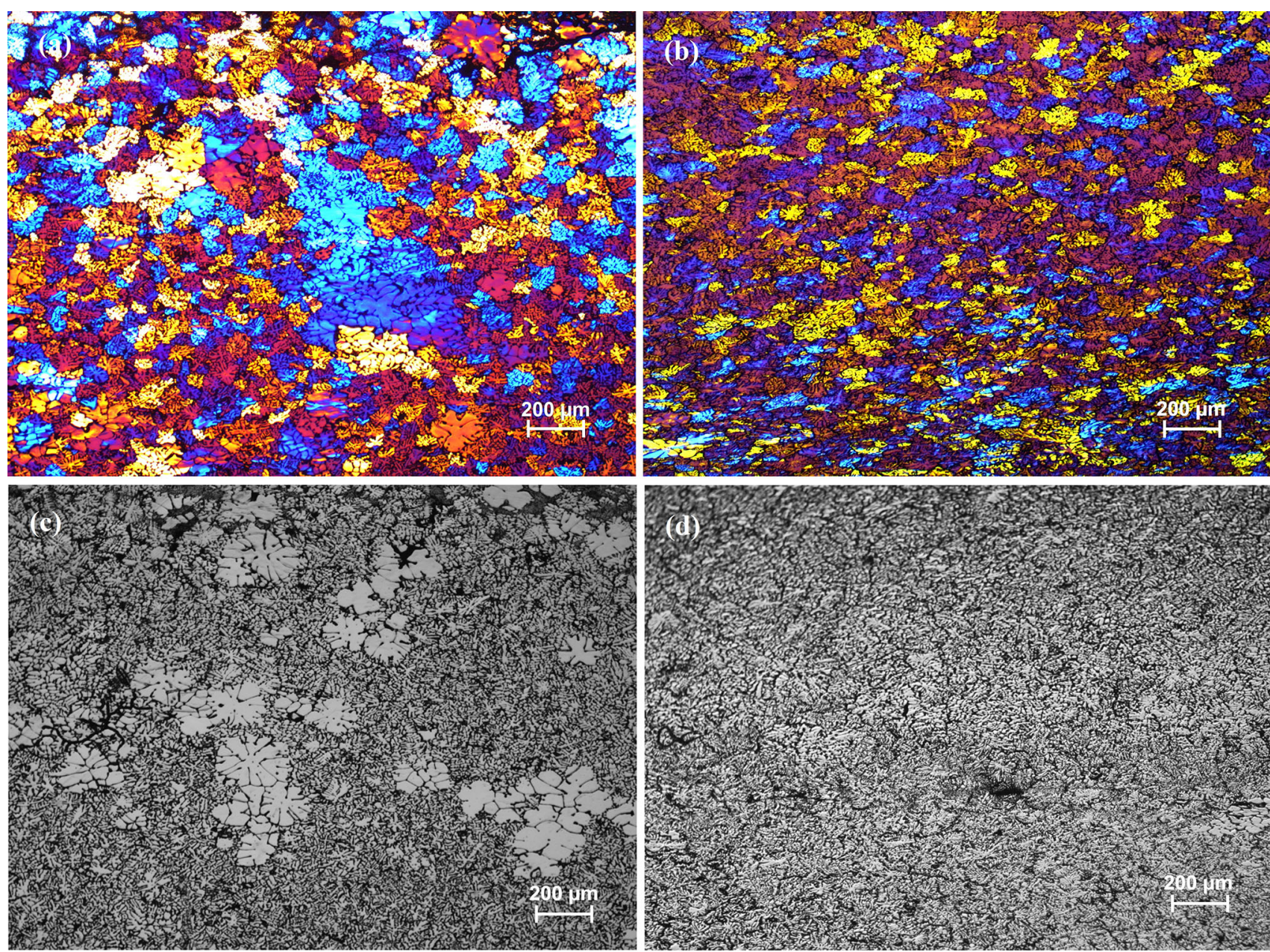

Fig. 1. Optical micrographs of transverse section TD of as-cast AA6111 alloy: (a, c) conventional TRC; (b, d) MC-TRC. 

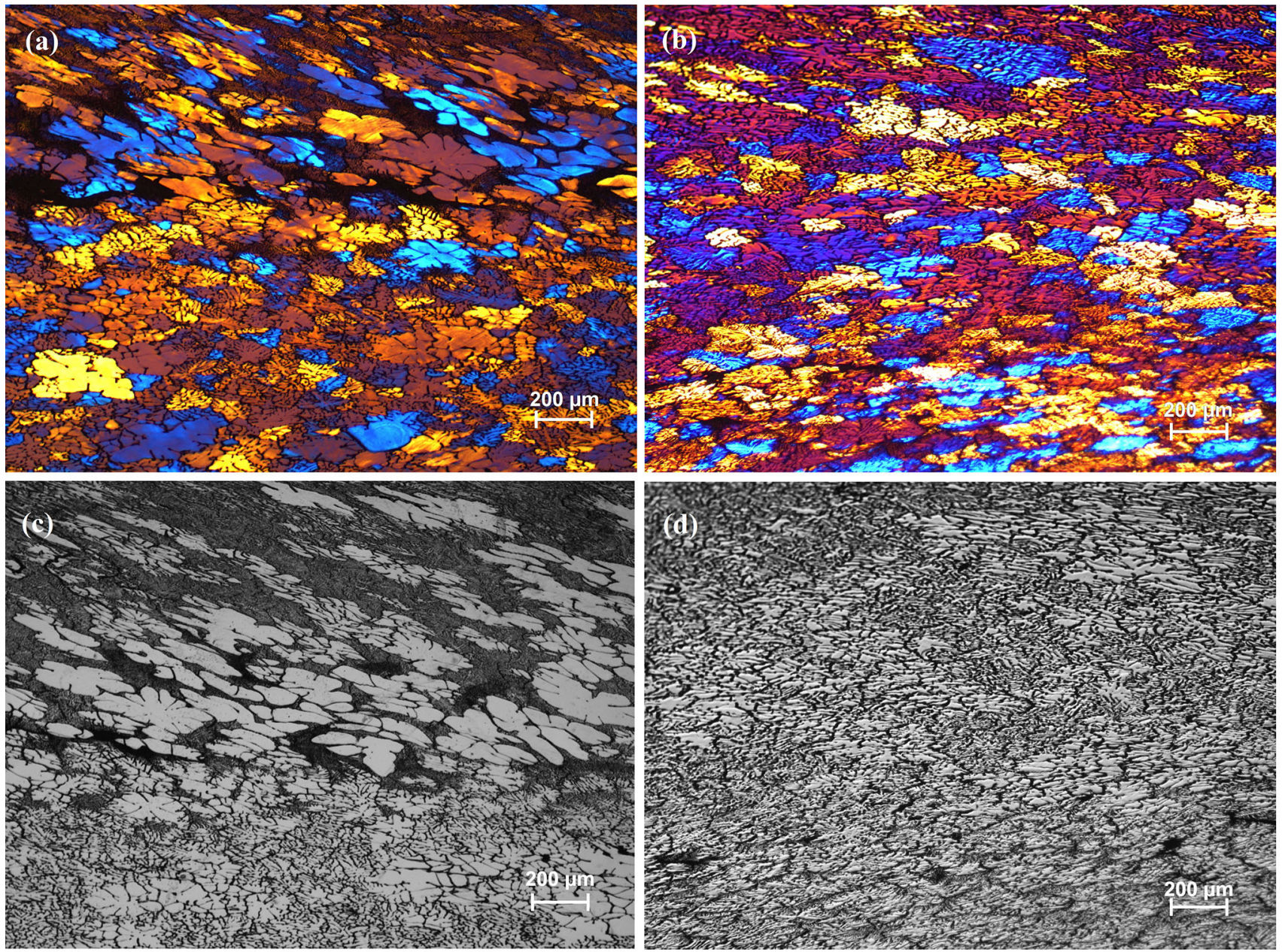

Fig. 2. Optical micrographs of longitudinal section RD of as-cast AA6111 alloy: (a, c) conventional TRC; (b, d) MC-TRC.

region will increase. Therefore, under certain operating conditions, MC-TRC strips will have a high degree of deformation throughout the thickness, which is the benefit of applying melt conditioning prior to casting. ${ }^{14}$

High shear melt conditioning of the liquid metal creates a high number of potent nucleating sites, such as oxide particles. ${ }^{16}$ These potent substrates nucleate the $\alpha-\mathrm{Al}$ and enhance to grow as equiaxed grains in a liquid having a uniform composition and temperature. ${ }^{17}$ It has been proved that the created oxides at the melt surface are entrained into the casting as films or as discrete particles. ${ }^{18}$ High shear melt conditioning disperses oxide films and clusters throughout the liquid uniformly. In $\mathrm{Al}-\mathrm{Mg}$ alloys, the formed oxide is spinel $\mathrm{MgAl}_{2} \mathrm{O}_{4}$ and the lattice misfit of $\alpha-\mathrm{Al}$ and $\mathrm{MgAl}_{2} \mathrm{O}_{4}$ is about $1.4 \%{ }^{17}$ Hence, for the melt with not enough nucleating particles, spinel particles will be potent nucleation sites for the $\alpha$-Al phase. ${ }^{19}$ Accordingly, the heterogeneous nucleation should be enhanced by the large numbers of potent oxide particles, leading to a fine equiaxed grain structure with eliminated centreline segregates in the MC-TRC strip. ${ }^{14}$

\section{Thermo-Mechanical Treatment}

Figure 4 shows the micrographs of homogenised strips of the TRC and MC-TRC process. The homogenised MC-TRC strip at $540^{\circ} \mathrm{C}$ for $8 \mathrm{~h}$ shows refined equiaxed grains while the conventional TRC consists of large dendritic grains.

Figure 5 shows the micrographs of cold-rolled and annealed strips of conventional and melt-conditioned twin roll casting strips. The $1-\mathrm{mm}$ gauge thickness of the cold-rolled MC-TRC strip exhibited very clear high shear deformation throughout the thickness compared with the conventional TRC strip in the longitudinal section $\mathrm{RD}$, as shown in Fig. $5 \mathrm{a}$ and $\mathrm{d}$.

Two annealing conditions were tested for the coldrolled strips. These conditions were either $520^{\circ} \mathrm{C}$ for $10 \mathrm{~min}$ or $450^{\circ} \mathrm{C}$ for $1 \mathrm{~h}$. After an annealing process at $520^{\circ} \mathrm{C}$ for $10 \mathrm{~min}$, the transverse section of the MC-TRC strip showed a clear grain recrystallisation rather than that with the conventional TRC strip with an average grain size $24 \mu \mathrm{m}$ and $34 \mu \mathrm{m}$, respectively, as shown in Fig. 5b and e. Annealing of strips at $450^{\circ} \mathrm{C}$ for $1 \mathrm{~h}$ caused partial 


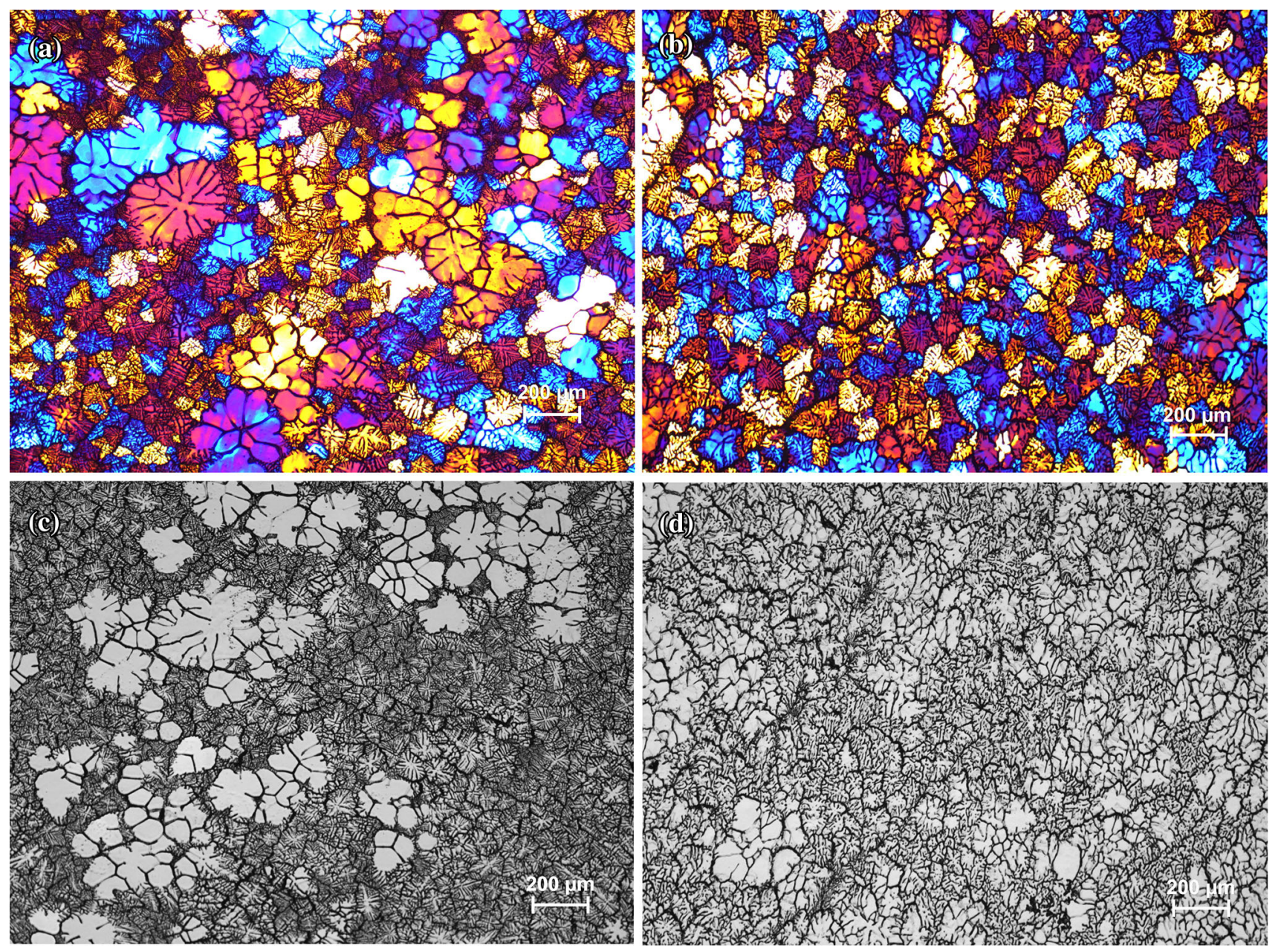

Fig. 3. Optical micrographs of normal direction ND of as-cast AA6111 alloy: (a, c) conventional TRC; (b, d) MC-TRC.
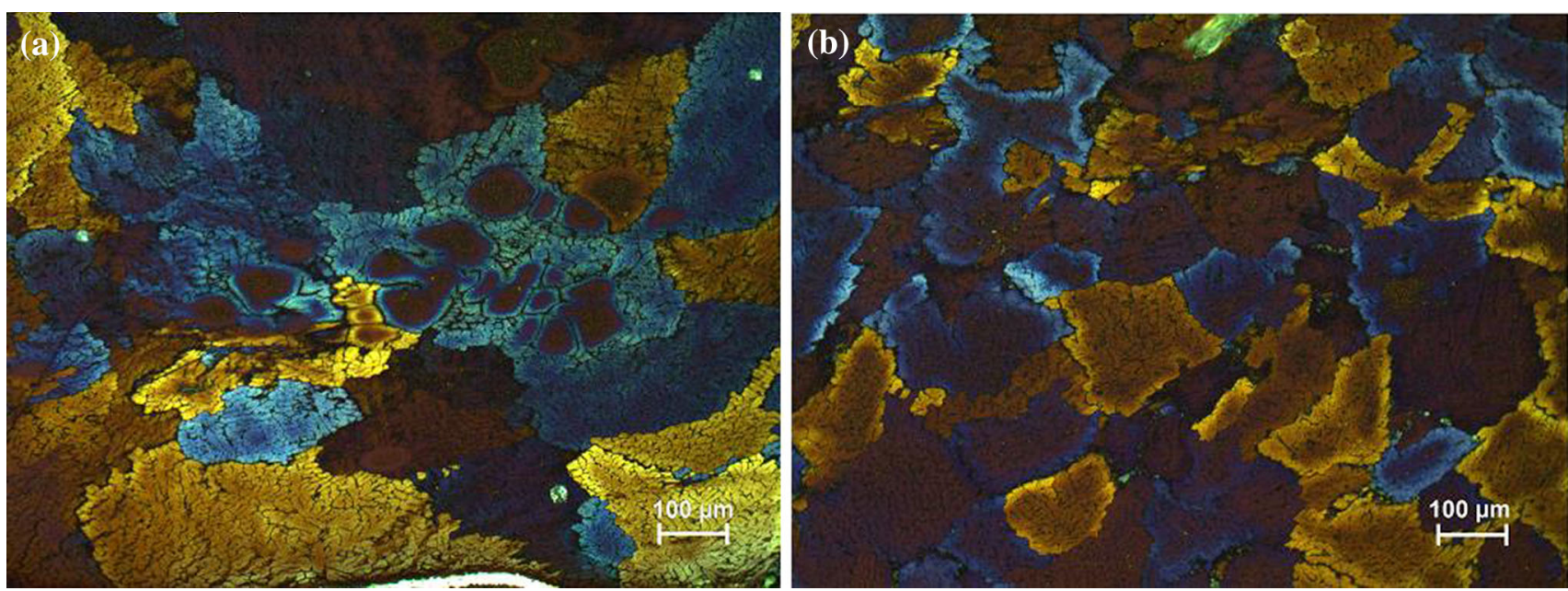

Fig. 4. Optical micrographs of homogenised AA6111 strips at $540^{\circ} \mathrm{C}$ for $8 \mathrm{~h}$ : (a) conventional TRC; (b) MC-TRC.

recrystallisation, grain deformation for MC-TRC strips and abnormal gain growth for TRC strips, as shown in Fig. 5c and f. The average grain size for conventional TRC and MC-TRC was $40 \mu \mathrm{m}$ and $28 \mu \mathrm{m}$, respectively.
The grain size distributions for all casting conditions are illustrated in Fig. 6. It is clear that the high shear melt conditioning can improve the melt quality by achieving a uniform distribution of 

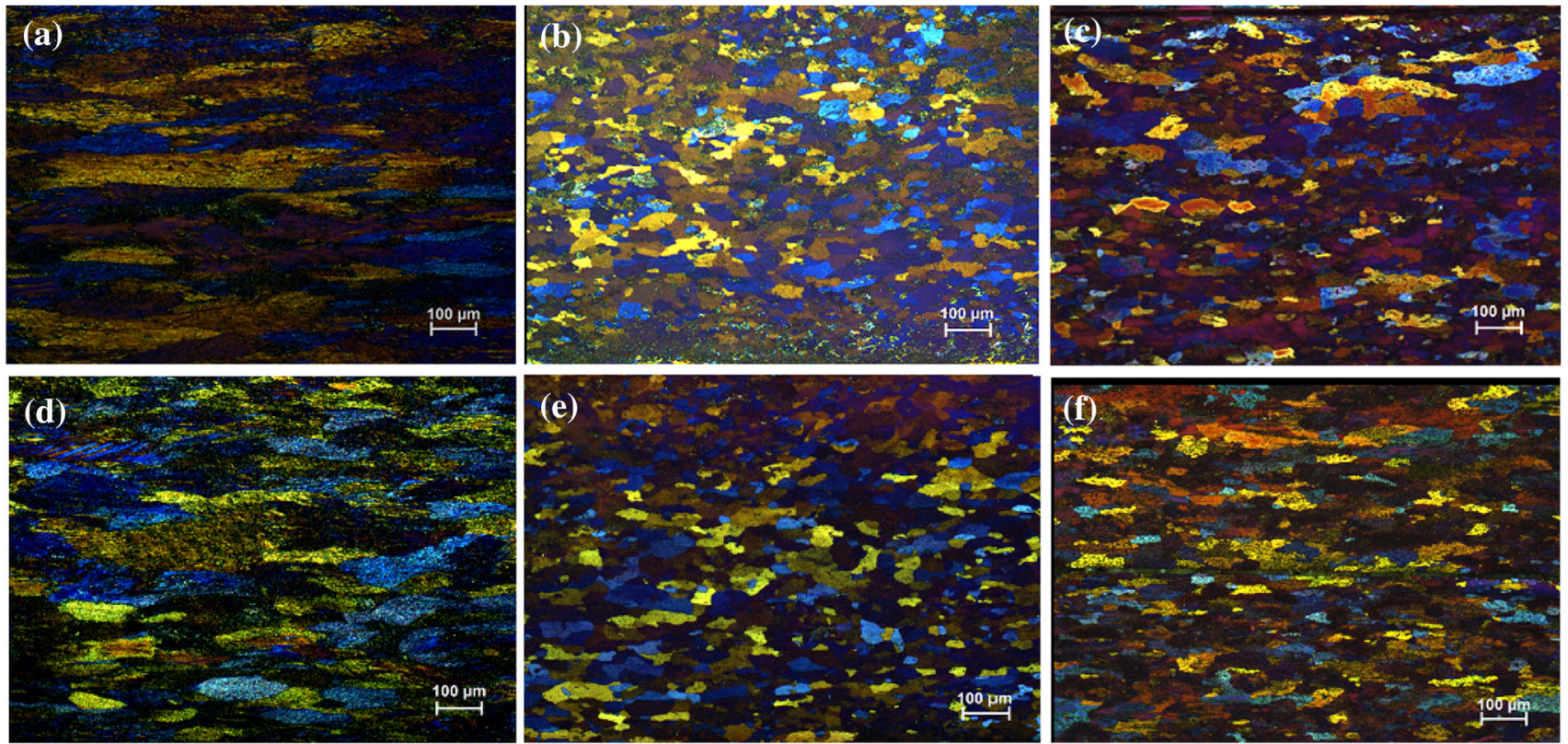

Fig. 5. Optical micrographs of: (a, d) cold-rolled TRC and MC-TRC; (b) annealed TRC strip at $520^{\circ} \mathrm{C}$ for 10 min; (c) annealed TRC strip at $450^{\circ} \mathrm{C}$ for $1 \mathrm{~h}$; (e) annealed MC-TRC strip at $520^{\circ} \mathrm{C}$ for $10 \mathrm{~min}$; (f) annealed MC-TRC strip at $450^{\circ} \mathrm{C}$ for $1 \mathrm{~h}$.

(a)

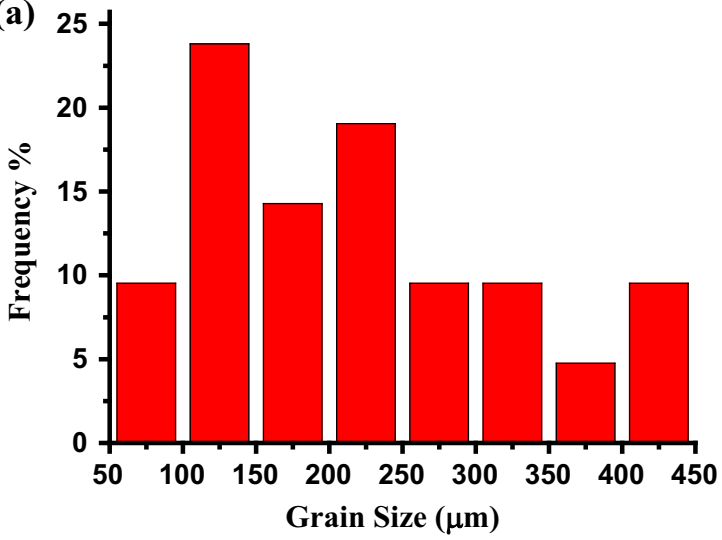

(c)

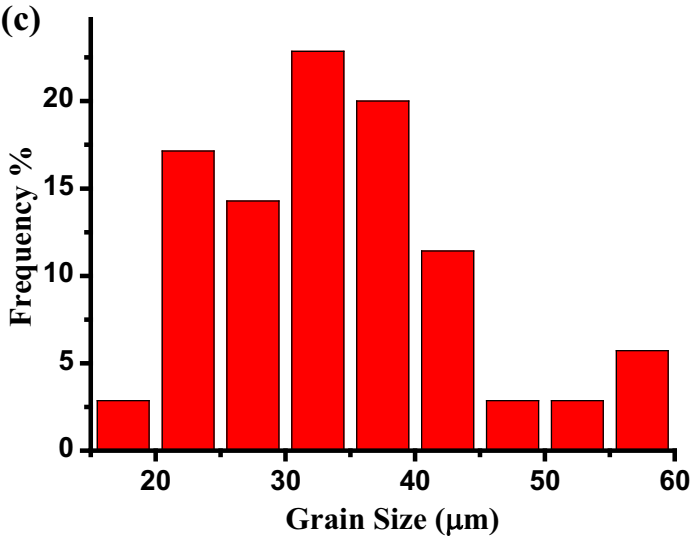

(b)
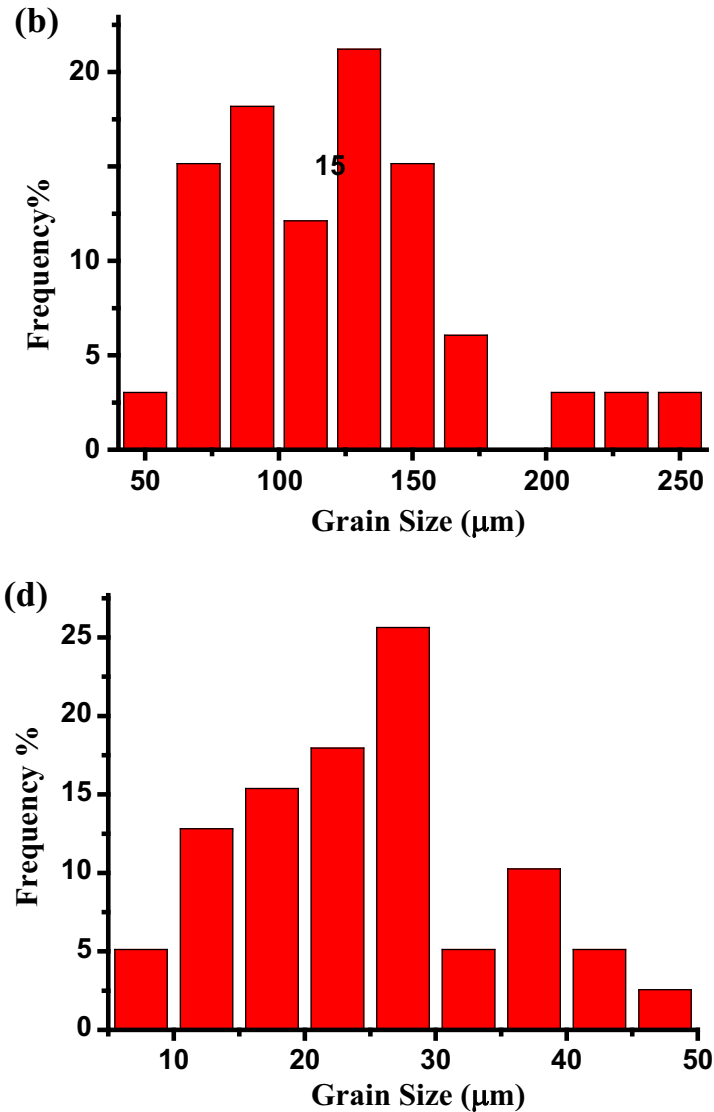

Fig. 6. Grain size distribution of: (a) as-cast TRC; (b) as-cast MC-TRC; (c) thermo-mechanical treated TRC at $520^{\circ} \mathrm{C}$ for $10 \mathrm{~min}$; (d) thermomechanical treated MC-TRC at $520^{\circ} \mathrm{C}$ for $10 \mathrm{~min}$. 
(a)

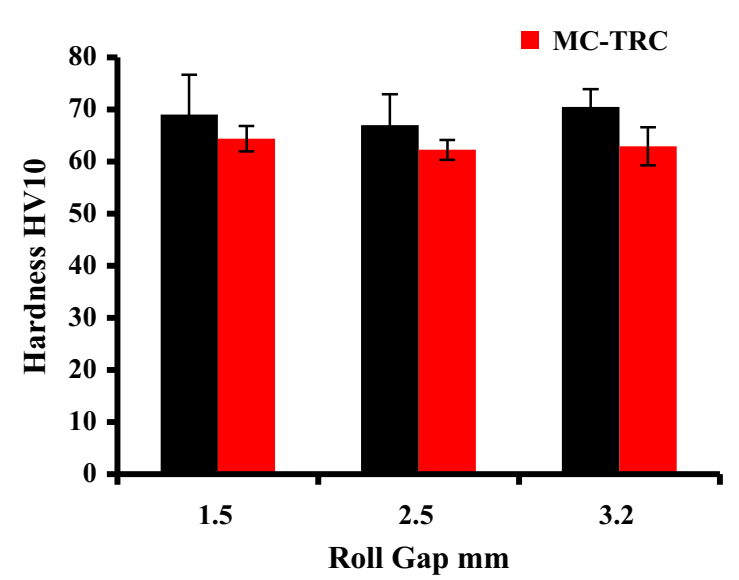

(b) a TRC

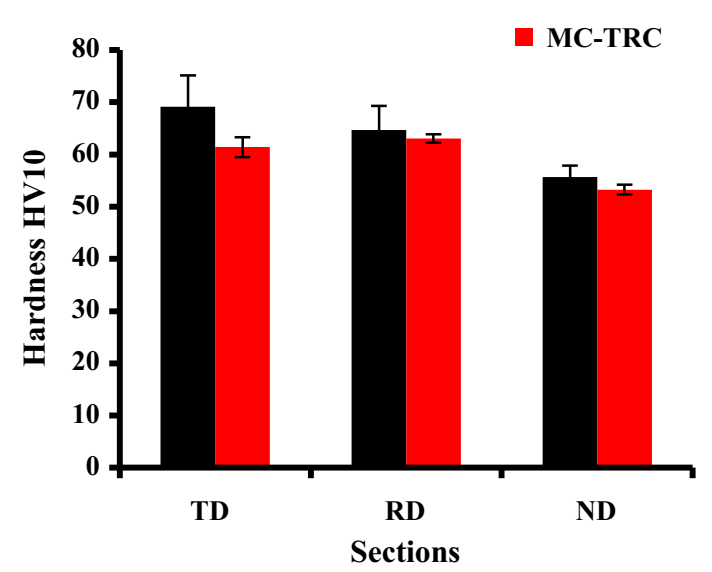

- TRC

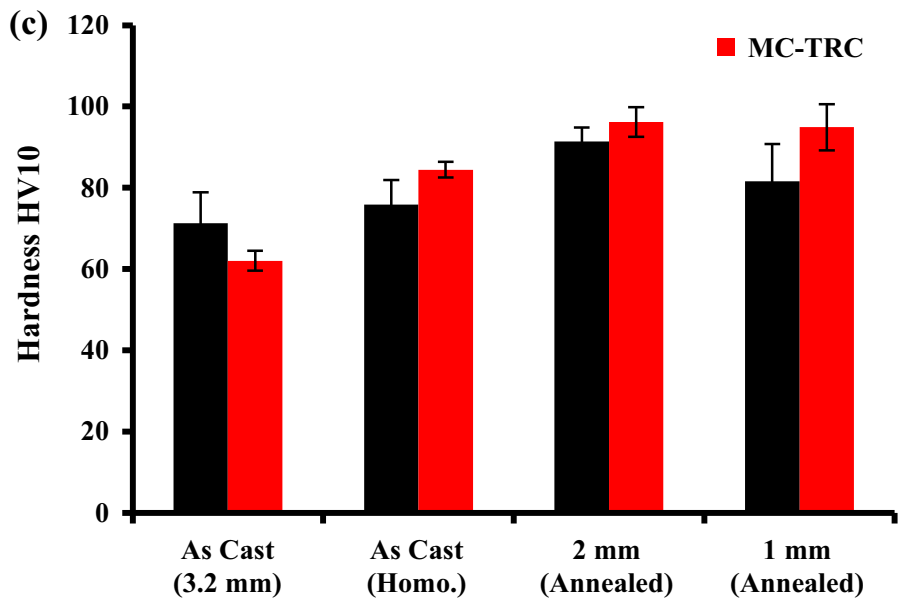

Fig. 7. Effect of intensive melt conditioning and thermo-mechanical treatment on the hardness of the AA6111 alloy strip: (a) for different roll gap casting; (b) along three directions of the 2.5-mm gap; (c) for different thermo-mechanical treatment conditions along TD of 2.5-mm roll gap casting.

nucleation substrates, which at the end creates a refined grain with good size distribution.

\section{Hardness}

Figure $7 \mathrm{a}$ and $\mathrm{b}$ shows the hardness results of ascast conventional TRC and MC-TRC strips for different roll gaps in the transverse direction TD and along three dimensions TD, RD and ND of the strip cast at $2.5-\mathrm{mm}$ roll gap. The results showed less hardness of the as-cast MC-TRC strips with a significant low standard deviation compared with the as-cast conventional TRC strips. As discussed before, high shear melt conditioning improves the microstructure by refining the grains and eliminates centre-line segregation, which at the end improves the mechanical properties. The reduction in hardness is an indication of the increases in the ductility.

It is clear that samples of MC-TRC with thermomechanical treatment showed higher hardness than conventional TRC after homogenisation and cold rolling to 2-mm gauge thickness, as shown in Fig. 7c. When a metal was deformed at room temperature (cold rolling), the microstructure becomes highly distorted because of an increase in the dislocation density. Therefore, cold rolling is referred to as strain hardening or work hardening, and as the strength and hardness of a metal increase, the ductility decreases. ${ }^{20}$ After the homogenisation process, the increase of the hardness is because most of the $\mathrm{AlCuMgSi}, \mathrm{CuAl}_{2}$ and $\mathrm{Mg}_{2} \mathrm{Si}$ were dissolved and plate-like $\beta-\mathrm{Al}_{5} \mathrm{FeSi}$ particles were transformed into spherical $\alpha$-AlFeMnSi particles. ${ }^{6}$

Eskin et al. ${ }^{21}$ noticed that in the 6000 series alloys there is an increase in the hardness after solution treatment and cold work. The strengthening of these alloys is due to the presence of $\mathrm{Mg}_{2} \mathrm{Si}$ precipitates in the alloys during solution treatment.

After cold rolling to 1-mm gauge thickness, there was a reduction in the hardness for the conventional TRC and MC-TRC strips compared with 2-mm 
gauge thickness strips. The reduction in hardness is due to the coalescence of the second phase precipitates into larger particles, which will cause some impediments to the dislocation movement. ${ }^{22}$

In conclusion, the cold-rolled MC-TRC sample showed better hardness than the cold-rolled TRC sample. Moreover, the microstructural analysis showed that the enhancement in the hardness of the MC-TRC strip was due to the elimination of centre-line segregation and the refined uniform microstructure. For deep investigation of the impact of high shear melt conditioning in twin roll casting, we are working on tensile and fracture tests alongside the texture evaluation for all strips. These results will be published in our next paper.

\section{CONCLUSION}

A conventional and high shear melt-conditioned twin roll casting with thermo-mechanical treatment was tested to produce good quality strips from commercial recycled AA6111 alloy. From microstructural evaluation along with hardness measurement, the following conclusions are made:

1. Applying high shearing melt conditioning prior to TRC casting can control the solidification during the casting process and produce good quality sheets from recycled AA6111 alloy.

2. MC-TRC strips showed fine equiaxed grain structure and eliminated centre-line segregation with full recrystallisation after thermomechanical treatment. MC-TRC with thermomechanical treatment can increase the impurity tolerance of recycled aluminium alloys picked from using scrap in the melt formulation.

3. Heat treatment of as-cast and cold-rolled AA6111 strips showed a clear grain recrystallisation at $520^{\circ} \mathrm{C}$ for $10 \mathrm{~min}$.

4. It is important to note that MC-TRC with thermo-mechanical treatment strips has higher hardness than conventional TRC.

\section{ACKNOWLEDGEMENTS}

The support from Primetals Technologies, UK, is acknowledged with gratitude. Funding was provided by Innovate UK (Grant No. R33599).

\section{OPEN ACCESS}

This article is distributed under the terms of the Creative Commons Attribution 4.0 International License (http://creativecommons.org/licenses/by/4.0/), which permits unrestricted use, distribution, and reproduction in any medium, provided you give appropriate credit to the original author(s) and the source, provide a link to the Creative Commons license, and indicate if changes were made.

\section{REFERENCES}

1. J. Cho, H. Kim, C. Lim, and S. Kang, Met. Mater. Int. 20, 647 (2014).

2. Y. Song, M. Cross, W. Rainforth, and B.P. Wynne, Mater. Sci. Forum 550, 211 (2007).

3. W. Zhang, B. Lin, Z. Luo, Y. Zhao, and Y. Li, J. Mater. Res. 30, 2474 (2015).

4. L. Zhang, Y. Wang, X. Yang, K. Li, S. Ni, Y. Du, and M. Song, J. Mater. Res. 20, 1360 (2017).

5. S. Zhang, B. Xiong, Y. Zhang, X. Li, F. Wang, Z. Li, and H. Liu, Mater. Sci. Forum 749, 223 (2013).

6. Y. Ji, F. Guo, and Y. Pan, Trans. Nonferrous Met. Soc. China 18,126 (2008).

7. Y. Osada, J. Mater. Sci. 39, 1227 (2004).

8. T. Haga, M. Ikawa, H. Watari, K. Suzuki, and S. Kumar, Mater. Trans. 46, 2596 (2005)

9. J.D. Hunt, M. Yun, S. Lockyer, and M.J. Heywood, Light Metals, ed. R. Huglen (1997), pp. 341-354.

10. J. Patel, H. Li, M. Xia, S. Jones, S. Kumar, K. O'Reilly, and Z. Fan, Mater. Sci. Forum 149, 794 (2014).

11. N. Barekar, S. Das, Z. Fan, R. Cinderey, and N. Champion, Mater. Sci. Forum 790, 285 (2014).

12. Z. Fan, Y. Wang, M. Xia, and S. Arumuganathar, Acta Mater. 57, 4891 (2009).

13. S. Kumar, N. Babu, G. Scamans, and Z. Fan, Mater. Sci. Technol. 27, 1833 (2011).

14. N. Barekar, S. Das, X. Yang, Y. Huang, O. El-Fakir, A Bhagurkar, L. Zhou, and Z. Fan, Mater. Sci. Eng. A 650, 365 (2016).

15. S. Kumar, N. Babu, G. Scamans, and Z. Fan, in Proceedings of the 12th International Conference on Aluminium Alloys, Yokohama, 5-9 Sept 2010.

16. H. Li, Y. Wang, and Z. Fan, Acta Mater. 60, 1528 (2012).

17. J. Patel, H. Li, M. Xia, S. Jones, S. Kumar, K. O'Reilly, and Z.Y. Fan, in 14th International Conference on Aluminium Alloys, ICAA2014, vol. 794, p.149 (2014).

18. J. Campbell, Metall. Mater. Trans. B 37, 857 (2006).

19. M. Zhang, P. Kelly, M. Qian, and J. Taylor, Acta Mater. 53, 3261 (2005).

20. ASTM Subject Guide, 2015, Heat Treating, Published by ASM International.

21. D. Eskin and M. Kharakterova, Mater. Technol. 35, 5 (2001).

22. H. Demir and S. Gündüz, Mater. Des. 30, 1480 (2009). 